Data de recebimento do artigo: 09-11-2018

Data de aceite do artigo: 17-01-2019

\title{
Indicadores de desempenho e engajamento profissional em organizações inovadoras
}

\author{
Marília Maria de Oliveira Santos \\ Mestre em Administração pelas Faculdades Metropolitanas Unidas (FMU). \\ E-mail: marilia.oliveirasantos04@gmail.com \\ Luiz Felipe Quel \\ Doutor em Administração pela Universidade de São Paulo (USP). \\ E-mail: luizfelipe@neovitta.com.br
}

\begin{abstract}
Almir Martins Vieira
Doutor em Educação pela Universidade Estadual Paulista "Júlio de Mesquita Filho" (Unesp). Coordenador do Programa de Pós-Graduação em Administração da Universidade Metodista de São Paulo. E-mail: almir.vieira@gmail.com
\end{abstract}

\begin{abstract}
Alessandro Marco Rosini
Doutor em Comunicação e Semiótica pela Pontifícia Universidade Católica de São Paulo (PUC-SP). E-mail: alessandro.rossini@yahoo.com
\end{abstract}

\section{Resumo}

O presente estudo tem como objetivo analisar a inclusão do índice de engajamento profissional dentre os indicadores do Balanced Scorecard [BSC], particularmente na perspectiva Aprendizagem e Crescimento. A abordagem metodológica tem natureza exploratória e caráter quantitativo, sendo a pesquisa realizada com a participação de 185 gestores de organizações que estão listadas como inovadoras e não inovadoras. O instrumento utilizado foi o Ultrech Work Engagement Scale [UWES], que mede os níveis do engajamento. O resultado revelou que engajamento profissional pode agregar valor aos indicadores de desempenho estratégico nas organizações inovadoras. Conclui-se que a prática de desenvolvimento de pessoas, que está inserida na perspectiva de Aprendizagem e Crescimento do $B S C$, adicionada ao indicador de engajamento profissional, traz resultados positivos para as organizações, criando um clima propício para que os funcionários se sintam mais engajado sem suas tarefas, mais interessados e inseridos em um ambiente que lhes traga mais confiança e bem-estar.

Palavras-chave: Engajamento. Indicadores de desempenho. Inovação. 


\title{
Performance indicators and professional engagement in innovative organizations
}

\begin{abstract}
This study has the objective of analyzing the inclusion of the professional engagement index into the Balanced Scorecard [BSC] indicators, particularly on the Learning and Growth perspective. The methodological approach was of exploratory nature, quantitative, with the participation of 185 managers of organizations that are listed as innovative or non-innovative. The tool used was the Ultrech Work Engagement Scale [UWES], that measures engagement levels. The result showed that professional engagement can add value to the strategic performance indicators on the innovative organizations. It is concluded that the practice of people development, which is inserted on the Learning and Growth perspective of BSC, added to the professional engagement index, brings positive results for the organizations, creating an appropriate environment for the employees to feel more engaged on their tasks, more interested and inserted in a place that provides them more confidence and welfare.
\end{abstract}

Keywords: Engagement. Innovation. Performance indicators.

\section{Como referenciar em APA:}

Santos, M. M. de O., Quel, L. F., Vieira, A. M., \& Rosini, A. M. (2019). Indicadores de desempenho e engajamento profissional em organizações inovadoras. R.G.Secr.,GESEC, 10(1), 192-212.

\section{Como referenciar em ABNT:}

SANTOS, M. M. O.; QUEL, L. F.; VIEIRA, A. M.; ROSINI, A. M. Indicadores de desempenho e engajamento profissional em organizações inovadoras. R.G.Secr.,GESEC, São Paulo, v. 10, n. 1, p. 192-212, jan.-abr. 2019.
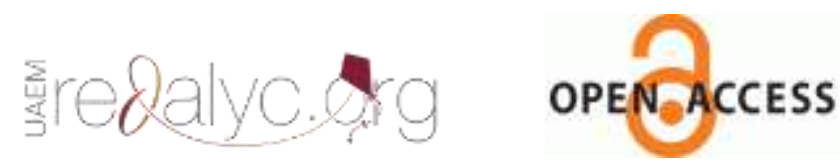


\section{Introdução}

Considerando a velocidade com que a sociedade constrói e destrói seus modelos em busca de aprimorar tecnologias, promover avanços nas relações sociais e outras transformações essenciais à continuidade do propósito humano, a inovação passa a ser um elemento central nas discussões sobre a maneira como as pessoas lidam e participam de um cenário no qual os resultados se colocam como desafios das organizações.

Este estudo contempla a relação entre os indicadores de desempenho das organizações e os níveis de engajamento profissional nas empresas que se intitulam inovadoras. Neste sentido, o objetivo deste trabalho é analisar a inclusão do índice de engajamento profissional dentre os indicadores do Balanced Scorecard [BSC], particularmente na perspectiva Aprendizagem e Crescimento. Justifica-se tal desafio pela consideração de que existem pontos de convergência entre a preocupação que as empresas demonstram no que tange aos resultados operacionais e o efetivo engajamento de seus profissionais na jornada pelo alcance desses objetivos e metas.

Importante reconhecer, de início, o significado dado ao contexto das empresas inovadoras. Não é recente a definição de inovação e ela vem passando por transformações e adaptações que em certo grau impactam na sua compreensão. Pode-se dizer que, em princípio, a inovação é uma mudança que gera uma nova perspectiva no desempenho das organizações (Drucker, 1987).

Em uma definição clássica, inovar é o processo de criação do novo e a destruição do que está obsoleto, do que precisa ser mudado, sendo a capacidade de ultrapassar a concorrência e criar um novo mercado para seus produtos (Schumpeter, 1961). Esta concepção é útil para tratar da gestão tecnológica e organizacional, pois está mais diretamente voltada para a melhoria da competitividade de uma empresa no mercado.

Dentre as referências conceituais mais utilizadas para analisar o processo de inovação está o Manual de Oslo (1997), que, por sua estrutura, permite a comparação de estatísticas internacionais e serve como base para a pesquisa da União Europeia sobre inovação, direcionando a Pesquisa Industrial sobre Inovação Tecnológica [PINTEC] do Instituto Brasileiro de Geografia e Estatística no Brasil [IBGE]. Ambas monitoram três tipos de inovação: produtos, processos e mudanças organizacionais, sendo que as informações coletadas 
abordam o comportamento inovador da empresa, os tipos de atividades empreendidas, os impactos percebidos e os incentivos e obstáculos à inovação.

Para fins desta pesquisa, as inovações organizacionais são relevantes à medida que dizem respeito a mudanças que ocorrem na estrutura gerencial da empresa, na forma de articulação entre suas diferentes áreas, na especialização dos trabalhadores, no relacionamento com fornecedores e clientes e nas múltiplas técnicas de organização dos processos de negócios.

Um dos indicadores de desempenho mais utilizados pelas organizações é o BSC, uma metodologia pautada na estratégia que visa expressar os esforços da empresa em busca de resultados claramente definidos (Norton \& Kaplan, 2004) e traduz a missão e a estratégia em objetivos e medidas enquadrados em quatro perspectivas diferentes: financeira, cliente, processos internos e aprendizagem e crescimento.

Neste trabalho, optou-se por enfatizar a perspectiva aprendizagem e crescimento, uma vez que envolve uma relação conceitual entre gestão de pessoas e aspectos relacionados ao engajamento humano.

Sobre engajamento no trabalho, o psicólogo norte-americano Kahn (1990) defendeu a ideia de que pessoas engajadas oferecem mais esforços em suas atividades, conseguindo resultados positivos para si e para a organização da qual fazem parte, visto que deve haver identificação com o trabalho desenvolvido.

O engajamento no trabalho é definido como um "estado positivo relacionado com o trabalho que se caracteriza pelo vigor, dedicação e concentração da atividade" (Schaufeli, Salanova, Gonzalez-Roma, \& Bakker, 2002, p. 72).

O mercado corporativo é cada vez mais competitivo e as grandes organizações buscam profissionais que sejam autoconfiantes, dedicados, concentrados e que contribuam com os resultados positivos da empresa (Dutra, 2014).

Considerando o exposto, a questão de pesquisa que se apresenta é: o engajamento profissional pode agregar valor aos indicadores de desempenho estratégico nas organizações inovadoras?

\section{Referencial Teórico}

\subsection{Indicadores de Desempenho}

O surgimento do Balanced Scorecard remonta a 1990, quando o Instituto Nolan Norton, unidade de pesquisa da KPMG, patrocinou um estudo de um ano entre diversas organizações 
intitulado Measuring Performance in the Organization of the Future, tendo como principal executivo David Norton, responsável pelo projeto de pesquisa, juntamente com o consultor acadêmico e professor da Universidade de Harvard, Robert Kaplan. O estudo foi incentivado pela crença de que os métodos existentes para avaliação do desempenho empresarial da época, em geral firmados nos indicadores contábeis e financeiros, estavam obsoletos. A pesquisa foi aplicada em várias empresas do segmento de manufatura e serviços da indústria pesada e de alta tecnologia. Tinha como objetivo desenvolver um novo modelo de medição do desempenho organizacional capaz de suprir as deficiências dos antigos modelos.

As discussões em grupo levaram a uma ampliação do scorecard, que resultou no chamado de Balanced Scorecard, organizado em torno de quatro perspectivas distintas financeira, do cliente, interna e de inovação e aprendizado. O nome reflete o equilíbrio entre objetivos de curto e longo prazo, entre medidas financeiras e não financeiras, entre indicadores de tendências (leading) e ocorrências (lagging), e entre as perspectivas interna e externa de desempenho.

Os objetivos e as medidas utilizadas no Balanced Scorecard não se limitam a um conjunto de medidas de desempenho financeiro e não financeiro, mas derivam de um processo hierárquico (top-down) da missão e da estratégia da organização.

O Balanced Scorecard deve traduzir a missão e a estratégia de uma unidade de negócios em objetivos e medidas tangíveis. Nesse processo, as medidas dizem respeito ao equilíbrio entre os vários indicadores externos, que equivalem aos clientes e acionistas, e os indicadores internos, que se referem aos processos internos, à inovação e ao aprendizado. Assim, o clássico referencial estratégico mencionado envolve o emprego de indicadores por meio de rastreamento de processos e avaliação de medidas fundamentais para definição dos objetivos; assim, o BSC se alinha à estratégia e proporciona uma melhor comunicação e estímulo para a melhoria do desempenho organizacional (Sharma, 2009), detectando dois tipos de clientes: os efetivos e os clientes em potencial.

A quarta perspectiva do Balanced Scorecard, aprendizado e crescimento, identifica a infraestrutura que a empresa deve construir para gerar crescimento e melhoria em longo prazo. Para Daft (2005), a perspectiva do aprendizado e crescimento mostra claramente o nível em que estão sendo administrados os recursos de capital humano para o futuro da empresa. 


\subsection{Engajamento}

Com o surgimento da Psicologia Positiva, os aspectos positivos da saúde e do bem-estar aumentaram significativamente na área organizacional. Um desses aspectos positivos é o engajamento no trabalho, que é considerado o oposto do burnout; enquanto os trabalhadores que têm burnout sentem-se exaustos e desumanizados, seus semelhantes engajados sentem-se vigorosos e entusiasmados em relação ao seu trabalho.

O professor William Kahn, da University School of Management Boston, foi o primeiro pesquisador que conceituou academicamente os estudos sobre engajamento no trabalho na década de 1990, no artigo intitulado Psychological conditions of personal engagement and disengagement at work (Kahn, 1990).

No começo da década de 1990, entendia-se o constructo engajamento no trabalho como “aproveitamento dos indivíduos da organização de seus próprios papéis de trabalho: no engajamento, as pessoas se beneficiam e se expressam a si mesmas física, cognitiva, emocional e mentalmente durante o desenvolvimento de seus papéis" (Kahn, 1990, p. 694).

O engajamento no trabalho pode ser caracterizado por energia, envolvimento e eficácia profissional (Maslach \& Leiter, 2008), os quais seriam os opostos diretos das três dimensões do burnout. Nessa perspectiva, o constructo é avaliado pelo padrão oposto dos escores das três dimensões do burnout, de acordo com o Maslach Burnout Inventory [MBI] (Maslach, Jackson \& Leiter, 1996).

Dessa forma, considera-se engajamento no trabalho a presença de resultados baixos em esgotamento emocional e desumanização, concomitantemente com resultados altos em eficácia profissional, como defendem Maslach, Schaufeli e Leiter (2001).

O engajamento no trabalho diz respeito a um estado positivo da mente, realizador e relacionado ao trabalho, sendo caracterizado pelo vigor, pela dedicação e pela concentração. O engajamento relaciona-se a um estado insistente, afetivo-cognitivo que não se foca em objeto, evento, indivíduo ou comportamento específico.

Segundo Schaufeli, Dijkstra e Vasquez (2013), um indivíduo engajado percebe quando está inspirado ao identificar que sente prazer nas atividades que realiza, e sua tarefa é executada de tal forma que ele e a organização são beneficiados em algum nível.

Reconhecer a carência desse engajamento é tão importante para a pessoa quanto para a equipe em que está inserida, além da organização em que atua. Esse reconhecimento se faz 
necessário para que a organização tome alguma ação e faça com que as pessoas possam se sentir inspiradas e entusiasmadas no trabalho novamente (Fernandes, Siqueira, \& Vieira, 2014).

O engajamento é sustentado por três níveis: vigor, dedicação e concentração. Os autores Schaufeli e Salanova (2007) apresentam o que cada nível de engajamento traz como característica, sendo o vigor caracterizado pelos altos níveis de energia e resiliência mental, pela vontade de investir no trabalho e persistência em situações de dificuldade. A dedicação refere-se a estar fortemente envolvido em seu trabalho e experimentar um senso de significância, entusiasmo, inspiração, orgulho e desafio. A concentração diz respeito a estar completamente concentrado e envolvido em seu trabalho, sendo que o tempo passa rapidamente e o indivíduo possui dificuldade em desapegar-se de seu trabalho.

\section{Metodologia}

Ancorado por abordagem quantitativa, estudo assumiu natureza exploratória, com base em pesquisa empírica e técnica de aplicação de questionário. A pesquisa foi aplicada em organizações inovadoras listadas entre as empresas mais inovadoras definidas no anuário produzido pelo Valor Inovação Brasil, pela Network $P w C$, e pelo jornal Valor Econômico, no ano de 2016. Esta listagem estabeleceu um ranking formado por corporações que inseriram processos de criação e incremento técnico constantes no cerne das estratégias, dos planos e das metas. Complementarmente, foram consultadas empresas brasileiras que não faziam parte da listagem inicial, com o intuito de comparação de resultados e contribuição para a análise dos resultados. No tocante ao número de participantes, obteve-se aceite de 108 gestores pertencentes a três empresas listadas no anuário mencionado. Os nomes das organizações não são indicados neste artigo, em razão do pedido de anonimato. Em relação às empresas não listadas no ranking, cuja atuação se enquadra nos segmentos levados em conta pelo anuário, obteve-se mais 77 respondentes, totalizando 185 participantes para a pesquisa.

O instrumento utilizado na pesquisa foi o questionário validado Utrecht Work Engagement Scale [UWES], elaborado pelos professores Wilmar Schaufeli e Arnold Bakker, em 2003, composto de 17 perguntas para se medir o nível de engajamento - vigor, dedicação e concentração. Esse instrumento é validado em vários países, com uma base de dados internacional de aproximadamente 30.000 respondentes, traduzido para 19 idiomas, sendo o 
questionário mais utilizado para avaliar o engajamento no trabalho em âmbito mundial (Bakker, Schaufeli, Taris, \& Bakker, 2008; Salanova \& Schaufeli, 2009).

O questionário é autoinforme, composto de 17 itens, com índices de consistência interna variando entre $\alpha=0,80$ a $\alpha=0,90$, que avaliam três dimensões (vigor, dedicação e concentração) e o escore geral do constructo, o que permite ter um indicador global dos resultados (Bakker et al., 2008; Bakker \& Leiter, 2010).

As respostas são fornecidas por uma escala tipo Likert de 7 pontos, indo de 0 a $6(0=$ nunca/ nenhuma vez e $6=$ sempre/todos os dias). $O$ manual foi traduzido e adaptado por Paulo C. Porto-Martins e Ana Maria T. Benevides-Pereira (GePEB-2008). Para evitar que o respondente seja influenciado pela conotação do termo Engajamento no trabalho, este não é utilizado no título do questionário. Ao invés disso, um termo mais neutro é usado, Questionário do bem-estar no trabalho, e UWES está entre parênteses.

De acordo com o UWES Manual - Português BR 27, o escore principal da escala das três subescalas do UWES é computado somando-se os escores de uma escala particular e dividindo-se a soma pelo número de itens da subescala envolvida. Um procedimento similar é seguido para o escore total. Além disso, o UWES mostra os escores de três subescalas e/ou um total que varia de 0 a 6 .

Originalmente, o UWES incluía 24 itens, dos quais nove eram itens de vigor, e oito, de dedicação, e sua maior parte consistia em frases do MBI - Maslow Burnout Inventory reescritas de forma positiva. Depois de uma avaliação psicométrica em duas diferentes amostras de trabalhadores e estudantes, sete itens se demonstraram inconsistentes e foram eliminados, sobrando 17 itens: 6 itens de vigor, 5 de dedicação e 6 de concentração (Schaufeli et al., 2002).

Tal qual mencionado anteriormente, o questionário foi aplicado em uma amostra de 185 participantes com nível de gestão, sendo 108 pertencentes às empresas consideradas inovadoras e os demais 77, pertencentes às empresas que não estão listadas como inovadoras. $\mathrm{O}$ critério utilizado para a escolha das empresas que não estão listadas como inovadoras foi não estarem elencadas como empresas inovadoras no ranking Valor Inovação Brasil, e estarem de acordo com o mesmo segmento das empresas listadas como inovadoras. Dos 108 indivíduos das empresas inovadoras, três tiveram problemas com as respostas, sendo excluídos da análise estatística. As empresas pesquisadas estão localizadas no estado de São Paulo, e os participantes eram de ambos os sexos. 


\section{Análise dos dados e resultados}

A Tabela 1 exibe as médias e os desvios-padrões de cada uma das perguntas, separadas conforme o nível de engajamento ao qual se refere, segundo tipologia de empresa.

Tabela 1 - Médias e desvios padrões das perguntas segundo nível de engajamento para empresas classificadas como inovadoras e demais empresas

\begin{tabular}{|c|c|c|c|c|c|}
\hline \multirow{2}{*}{ Níveis } & \multirow{2}{*}{ Perguntas } & \multicolumn{2}{|c|}{ Inovadoras } & \multicolumn{2}{|c|}{ Demais } \\
\hline & & Média & D.P. & Média & D.P. \\
\hline \multirow{6}{*}{$\stackrel{\ddot{\circ}}{\stackrel{\leftrightarrow}{\circ}}$} & Em meu trabalho, sinto-me repleto (cheio) de energia & 4,45 & 1,37 & 3,26 & 1,38 \\
\hline & No trabalho, sinto-me com força e vigor (vitalidade) & 4,35 & 1,47 & 3,40 & 1,30 \\
\hline & Quando me levanto pela manhã, tenho vontade de ir trabalhar & 4,37 & 1,56 & 3,69 & 1,22 \\
\hline & Posso continuar trabalhando durante longos períodos de tempo & 4,11 & 1,55 & 3,27 & 1,28 \\
\hline & Em meu trabalho, sou uma pessoa mentalmente resiliente (versátil) & 4,54 & 1,23 & 3,36 & 1,19 \\
\hline & No trabalho, sou persistente mesmo quando as coisas não vão bem & 4,67 & 1,30 & 3,44 & 1,34 \\
\hline \multirow{5}{*}{ 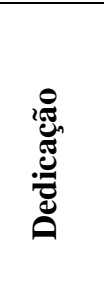 } & Eu acho que o trabalho que realizo é cheio de significado e propósito & 4,64 & 1,35 & 3,61 & 1,29 \\
\hline & Estou entusiasmado com meu trabalho & 4,42 & 1,50 & 3,23 & 1,26 \\
\hline & Meu trabalho me inspira & 4,32 & 1,65 & 3,47 & 1,17 \\
\hline & Estou orgulhoso com o trabalho que realizo & 4,75 & 1,49 & 3,82 & 1,24 \\
\hline & Para mim, meu trabalho é desafiador & 4,56 & 1,56 & 3,18 & 1,34 \\
\hline \multirow{6}{*}{ ن } & O "tempo voa" quando estou trabalhando & 5,01 & 1,27 & 3,53 & 1,24 \\
\hline & Quando estou trabalhando, esqueço tudo o que se passa ao meu redor & 3,86 & 1,65 & 3,40 & 1,32 \\
\hline & Sinto-me feliz quando trabalho intensamente & 4,38 & 1,42 & 3,56 & 1,09 \\
\hline & Sinto-me envolvido com o trabalho que faço & 4,81 & 1,46 & 3,34 & 1,17 \\
\hline & "Deixo-me levar" pelo meu trabalho & 3,63 & 1,83 & 3,39 & 1,16 \\
\hline & É difícil desligar-me do trabalho & 3,57 & 1,66 & 3,61 & 1,17 \\
\hline
\end{tabular}

Fonte: Dados da pesquisa (2018).

Percebe-se que a pergunta com maior valor médio para as empresas classificadas como inovadoras é "O 'tempo voa quando estou trabalhando", com média de 5,01, pertencente ao nível de engajamento concentração; já para as demais empresas, a pergunta com maior média é a "Estou orgulhoso com o trabalho que realizo" $(3,82)$, do nível dedicação. No outro extremo, as perguntas com menores valores médios para as empresas classificadas como inovadoras e as demais, respectivamente, são "É difícil desligar-me do trabalho", do nível concentração $(3,57)$ e "Para mim meu trabalho é desafiador", do nível dedicação $(3,18)$.

De forma geral, nota-se que as médias de respostas dos funcionários das empresas inovadoras são maiores do que as médias apresentadas pelos funcionários das demais empresas, 
exceção feita à pergunta "É difícil desligar-me do trabalho", apontada com média levemente inferior por funcionários de empresas inovadoras do que por aqueles das demais empresas.

A pergunta com maior discrepância média entre as duas tipologias de empresa foi “ $\mathrm{O}$ 'tempo voa' quando estou trabalhando" (média de 5,01 para empresas inovadoras versus média de 3,53 para as demais), seguida da pergunta "Sinto-me envolvido com o trabalho que faço" (médias de 4,81 para empresas inovadoras e 3,34 para as demais), ambas contidas nos níveis de engajamento concentração.

Conforme ilustrado no manual de utilização da UWES no Brasil, a obtenção dos três níveis de engajamento ocorre calculando-se a média das respostas dadas às perguntas que compõem cada nível; o engajamento total é obtido com a média das 17 respostas dadas às perguntas considerando a escala interna do instrumento.

Tabela 2 - Distribuição das respostas referentes aos três níveis de engajamento e engajamento total para empresas classificadas como inovadoras e demais empresas

\begin{tabular}{c|cccc|cccc}
\hline \multirow{2}{*}{ Estatísticas } & \multicolumn{4}{|c|}{ Inovadoras } & \multicolumn{4}{c}{ Demais } \\
\cline { 2 - 8 } & $\mathrm{V}$ & $\mathrm{D}$ & $\mathrm{C}$ & $\mathrm{E}$ & $\mathrm{V}$ & $\mathrm{D}$ & $\mathrm{C}$ & $\mathrm{E}$ \\
\hline Mínimo & 1,00 & 0,20 & 0,83 & 0,76 & 1,50 & 2,20 & 2,50 & 2,82 \\
$5 \%$ & 2,00 & 1,80 & 2,17 & 1,94 & 2,33 & 2,40 & 2,67 & 2,94 \\
$25 \%$ & 3,83 & 3,80 & 3,67 & 3,82 & 3,00 & 3,20 & 3,17 & 3,29 \\
$50 \%$ & 4,67 & 5,00 & 4,33 & 4,59 & 3,50 & 3,40 & 3,50 & 3,41 \\
$75 \%$ & 5,17 & 5,40 & 5,00 & 5,18 & 3,83 & 3,80 & 3,83 & 3,65 \\
$95 \%$ & 5,67 & 6,00 & 5,50 & 5,65 & 4,33 & 4,40 & 4,33 & 3,94 \\
Máximo & 6,00 & 6,00 & 5,83 & 5,88 & 4,67 & 4,80 & 4,67 & 4,24 \\
\hline Média & 4,42 & 4,54 & 4,21 & 4,38 & 3,40 & 3,46 & 3,47 & 3,45 \\
Desvio Padrão & 1,14 & 1,34 & 1,09 & 1,13 & 0,56 & 0,56 & 0,49 & 0,29 \\
\hline
\end{tabular}

Fonte: Dados da pesquisa (2018).

Legenda: V = Vigor; $\mathrm{D}=$ Dedicação; $\mathrm{C}=$ Concentração; $\mathrm{E}=$ Engajamento.

A Tabela 2 apresenta a distribuição dos níveis de engajamento, além da média e do desvio-padrão para empresas inovadoras e demais (Bussab \& Morettin, 2013).

Observados os valores da Tabela 2, tem-se que empresas inovadoras possuem maiores níveis de engajamento do que as demais. Este resultado é observado por meio dos valores da mediana e do máximo de cada nível de engajamento (e o total). Segundo a tipologia da empresa, $50 \%$ dos funcionários das empresas inovadoras responderam possuir engajamento total acima de 4,59 - e o maior valor obtido foi de 5,88 -, enquanto que 50\% dos funcionários das demais empresas disseram ter um nível total de engajamento da ordem de 3,41, com o máximo de 4,24 (menor do que a mediana das empresas inovadoras). O mesmo é observado para cada um dos três níveis que compõem o engajamento total. 
Outra questão a ser observada refere-se à distribuição dos dados. Considerando que o instrumento Utrecht Work Engagement Scale [UWES] é uma escala de 7 pontos (0 a 6), as respostas das empresas inovadoras são levemente assimétricas positivamente, enquanto as das demais empresas apresentam resultados mais simétricos, em torno da média, corroborando com a apresentação de que, aparentemente, empresas inovadoras têm funcionários mais engajados - em todos os níveis - do que os das demais empresas.

Os dados indicam que as respostas oriundas das organizações listadas como inovadoras apresentam resultados mais positivos do que os das demais empresas. Tal resultado atesta o que os autores Schaufeli, Dijkstra e Vasquez (2013) defendem, sendo que um indivíduo engajado percebe-se estar inspirado ao identificar que sente prazer nas atividades que realiza, sua tarefa é executada de tal forma que ele e a organização são beneficiados em algum nível.

A fim de entender as diferenças estatísticas do que foi descrito anteriormente, foi executado um teste-t com o uso do software estatístico SPSS (versão 20.0). Este é um teste paramétrico que tem como premissa que os dados apresentem distribuição normal (Hair, Black, Babin, Anderson, \& Tatham, 2006). Para a avaliação deste quesito, foi utilizado o teste de Kolmogorov-Smirnov, não rejeitando a hipótese nula de normalidade ( $p>0,05)$.

Tabela 3 - Resultados do teste-t e diferença de médias, segundo nível de engajamento, comparando empresas classificadas como inovadoras com demais empresas

\begin{tabular}{l|cc|ccc}
\hline $\begin{array}{c}\text { Níveis de } \\
\text { Engajamento }\end{array}$ & Estatística t & p-valor & $\begin{array}{c}\text { Diferenças } \\
\text { de Médias }\end{array}$ & $\begin{array}{c}\text { Desvio Padrão } \\
\text { Diferença de } \\
\text { Médias }\end{array}$ & $\begin{array}{c}\text { Intervalo de Confiança } \\
\text { Diferença de Médias (95\%) }\end{array}$ \\
\hline Vigor & 7,909 & 0,000 & 1,01 & 0,13 & $0,76-1,26$ \\
Dedicação & 7,402 & 0,000 & 1,08 & 0,15 & $0,79-1,36$ \\
Concentração & 6,129 & 0,000 & 0,74 & 0,12 & $0,50-0,98$ \\
\hline Engajamento & 8,119 & 0,000 & 0,93 & 0,12 & $0,71-1,16$ \\
\hline
\end{tabular}

Fonte: Dados da pesquisa (2018).

Conforme o que se apresenta na tabela 3, constata-se diferença estatística entre os níveis de engajamento quando comparadas empresas classificadas como inovadoras e demais empresas $(\mathrm{p}<0,001)$, comprovando o que havia sido observado descritivamente.

Quando comparadas as médias de cada um dos níveis, é possível notar que, de forma geral, a diferença entre os níveis de engajamento dos funcionários das duas tipologias avaliadas é de cerca de 1 ponto a mais para aqueles das empresas classificadas como inovadoras, sendo 
o nível de concentração aquele com menor diferença, da ordem de 0,74 , e a dedicação, o nível de maior discrepância entre empresas: 1,08.

\section{Discussão}

Especificamente na perspectiva aprendizagem e crescimento, o índice de engajamento profissional pode trazer um impacto diferente entre empresas, pois existem evidências empíricas de que indivíduos de empresas classificadas como inovadoras demonstram maior nível de engajamento, conforme os autores Schaufeli e Salanova (2007), que afirmam que indivíduos engajados apresentam maior habilidade em conduzir sua tarefa e facilidade em ter a aprendizagem, aproveitando e associando as oportunidades que surgem, colaborando assim para os resultados organizacionais.

A perspectiva aprendizagem e crescimento do BSC, a que mais corresponde à gestão estratégica de pessoas, diz que funcionários satisfeitos são precondição para o aumento da produtividade, da capacidade de resposta, da qualidade e da melhoria do serviço aos clientes, conforme atestam os autores Kaplan e Norton (1997).

Pessoas mais concentradas em suas tarefas (Csikszentmihalyi, 1992) tendem a ter um foco maior na execução de seu trabalho, como se constata pelo alto índice das médias para empresas listadas como inovadoras. Conhecer os mecanismos pelos quais as pessoas possam ser mais estimuladas a apresentar melhores níveis de desempenho às empresas é fator de sucesso no resultado final, indicando que estas organizações se preocupam com os seus profissionais.

Essas empresas que estão listadas como inovadoras, são de grande porte, possuem todo um ambiente agradável, de confiança, além de benefícios, salários e segurança, ou seja, existe todo um cenário propício para que as pessoas consigam desempenhar um melhor trabalho e tragam melhores resultados, assim tornando o negócio da empresa mais competitivo, com colaboradores mais felizes e propensos a responder de forma positiva aos desafios que lhe são propostos no dia a dia (Bakker, Demerouti, \& Verbeke, 2004; Siqueira, \& Gomide Jr., 2004; Vazquez, Magnan, Pacico, Hutz, \& Schaufeli, 2016). Tal cenário corrobora com o que os autores Bakker e Schaufeli (2000) e Medhurst e Albrecht (2016) afirmam, mostrando que profissionais engajados vivenciam relação de bem-estar e comportamento proativo, 
propiciando suprir as necessidades das organizações modernas, tendo em vista que apresentam um ótimo desempenho, disponibilizando um serviço de qualidade.

Sob a ótica do constructo de indicadores de desempenho, especificamente a perspectiva do Balanced Scorecard “aprendizagem e crescimento”, Kaplan e Norton (1997) são categóricos em afirmar que as empresas que estarão sempre à frente do tempo são aquelas que investem em seu capital humano por meio de treinamentos, reciclagem de seus funcionários, satisfação e retenção, junto com o acompanhamento de suas performances e habilidades para que assim estivessem em um ambiente competitivo.

Os autores Kaplan e Norton (1997) mencionam que, para os profissionais manterem suas mentes e capacidades criativas, devem ser continuamente incentivados no sentido dos objetivos organizacionais, e para isso três medidas são essenciais: satisfação, retenção e produtividade dos funcionários, de forma que os profissionais poderão dar uma resposta positiva.

O menor valor médio das empresas listadas como inovadoras na questão "É difícil desligar-me do trabalho", indica que, quando uma empresa oferece condições positivas de trabalho e alegria, como defendem os autores Demerouti, Bakker e Leiter (2014, p. 215), não há razão para o profissional ficar "ligado ao trabalho", ou preso; ele faz, entrega o trabalho e não tem dificuldade em se desligar de sua tarefa.

Ao analisarmos o menor valor médio das empresas listadas como não inovadoras na questão "Para mim, meu trabalho é desafiador", podemos refletir que quando o profissional não se sente valorizado em sua organização, ele provavelmente não se sentirá desafiado e não terá vontade e motivação para desempenhar um bom papel pela empresa onde trabalha, como apontam os autores Boyatzis e Skelly (1995), que defendem que a relação entre os valores pessoais e da empresa com o desempenho organizacional é altamente significativa, algo apontado também por Siqueira e Vieira (2012).

No tocante ao que se apresenta na tabela 2, podemos dizer que empresas inovadoras possuem maiores níveis de engajamento do que as empresas que não estão listadas como inovadoras. Este resultado é observado por meio dos valores da mediana e do máximo de cada nível de engajamento. Segundo a tipologia da empresa: $50 \%$ dos funcionários das empresas inovadoras responderam possuir engajamento total acima de 4,59 - e o maior valor obtido foi de 5,88 -, enquanto que $50 \%$ dos funcionários das demais empresas disseram ter um nível total de engajamento da ordem de 3,41, com o máximo de 4,24 (menor do que a mediana das 
empresas inovadoras). Evidencia-se, portanto, que quanto mais se investe nos colaboradores, mais retorno se obtém para o negócio da organização, resgatando a afirmação de Senge (1999), para quem as organizações teriam sucesso no futuro se descobrissem - nas pessoas - o comprometimento e a capacidade de aprender em todos os níveis da organização. Assim, o resultado para as empresas listadas como inovadoras alcançou em todos os níveis o engajamento, exemplificado pelo cuidado que a organização tem com a saúde e com a qualidade de vida dos colaboradores (Machado, Porto-Martins, \& Amorim, 2012). Resgatando a afirmação de Porter (2000), quando o profissional tem segurança no ambiente organizacional onde está inserido, a execução de seu trabalho vem com a mesma qualidade e investimento por ele recebidos, postura que faz parte da construção do valor.

Estudos mostram que pessoas engajadas apresentam um melhor desempenho e os setores dos quais fazem parte apresentam um melhor resultado (Bakker \& Leiter, 2010). Schaufeli e Salanova (2008) apontam que aqueles que se sentem engajados em relação ao seu trabalho demonstram: maior satisfação com o trabalho, não mostram intenção em deixar a organização, aparentam boa saúde mental, apresentam comportamento proativo, iniciativa pessoal e motivação para aprender, têm a condição de estarem mais concentrados em suas atividades e sentem o tempo passar rapidamente. Tal panorama mantém a estabilidade do trabalhador, assim como previne para a organização o problema do turnover, que tanto afeta a imagem da empresa.

Analisando as empresas não listadas como inovadoras com o resultado total de engajamento, constata-se resultado bem abaixo em comparação com as empresas listadas como inovadoras. Reconhecer a carência desse engajamento ou analisar o resultado baixo é tão importante para a pessoa quanto para a equipe na qual ela está inserida (como também para a organização em que atua), pois esse índice serve para que decisões e ações sejam tomadas com clareza, de modo que os indivíduos podem voltar a ter vontade, inspiração e entusiasmo de pertencer àquele grupo organizacional (Fernandes, Siqueira, \& Vieira, 2014).

A relação entre valores pessoais e da empresa com o desempenho organizacional é altamente significativa, conforme alertam Boyatzis e Skelly (1995). Ao detectarem tal importância, Tamayo e Gondim (1996) demonstraram que os valores organizacionais contribuem para a identidade empresarial, determinando a percepção dos problemas e as formas de solucioná-los, envolvendo a motivação dos colaboradores (Siqueira \& Vieira, 2012). 
De acordo com Schaufeli e Salanova (2008), para aumentar o engajamento no trabalho, é essencial incitar e manter as "gain spirals". Uma gain spiral pode ser definida como um conjunto de relações cíclicas em que diferentes dimensões positivas são associadas, e os benefícios associados com essas dimensões positivas são amplificados com o decorrer do tempo (Freitas, Silva, Damásio, Koller \& Teixeira, 2016).

Dessa forma, Schaufeli e Salanova (2008) afirmam que o engajamento no trabalho pode ser aumentado ao estimular os diferentes aspectos dessa espiral e, com base nessa premissa, apresentam uma série de estratégias de Recursos Humanos que podem ser utilizadas para estimular o engajamento no trabalho.

O fato de uma empresa ser inovadora e estimular o pensamento criativo de seus colaboradores pode ser fundamental para que todo esse envolvimento, aliado a um ambiente propício e boa liderança, resulte em altos níveis de engajamento. Entretanto, o contrário também pode deflagrar desengajamento, pois vários autores relacionam o engajamento no trabalho com existência de recursos (Halbesleben Jonathon \& Wheeler, 2008; Bakker, Demerouti, \& Verbeke, 2004; Simpson, 2009; Le Blanc, Schaufelli, Salanova, Lhorens, \& Nap, 2009), sejam eles internos - resiliência, motivação, satisfação com a vida e com o trabalho -, sejam eles externos - clima organizacional, suporte social e feedback. Esses trabalhos têm relação com a teoria da conservação de recursos de Hobfoll (2001), segundo a qual as pessoas procuram obter, reter e proteger as coisas que elas valorizam, incluindo recursos materiais, sociais, pessoais, ou até mesmo a energia.

Outro aspecto a ser observado refere-se à distribuição dos dados. Considerando que o instrumento Utrecht Work Engagement Scale [UWES] é uma escala de 7 pontos (0 a 6), as respostas das empresas inovadoras são levemente assimétricas positivamente, ou seja, respondem de forma mais ampla, têm uma visão maior, um entendimento alargado das situações, conseguem enxergar o todo, permitindo contribuir mais e melhor dentro da organização.

Resgatando o que se apresenta na tabela 3, quando comparadas as médias de cada um dos níveis, é possível notar que, de forma geral, a diferença entre os níveis de engajamento dos funcionários das duas tipologias avaliadas é de cerca de 1 ponto a mais para aqueles das empresas classificadas como inovadoras, sendo o nível de concentração aquele com menor diferença, da ordem de 0,74, e a dedicação, o nível de maior discrepância entre empresas: 1,08. 
Juntamente com a satisfação no trabalho, dentre os indicadores negativos do empregado, o bem-estar também tem sido usado como preditivo do baixo desempenho no trabalho. Por exemplo, a saúde não estando em boa situação (Shi, Sears, Coberley \& Pope, 2013), exaustão emocional (Taris, 2006; Taris \& Schreurs, 2009), e burnout (Demerouti, Bakker \& Leiter, 2014) foram conectados para reduzir o desempenho no trabalho.

\section{Considerações Finais}

Este estudo contemplou o índice de engajamento profissional dentre os indicadores do BSC, particularmente na perspectiva aprendizagem e crescimento, ao verificar o nível de engajamento nas empresas listadas como inovadoras e das empresas não listadas como inovadoras, comparando a média do indicador de engajamento dos profissionais das empresas. De forma geral, nota-se que as médias de respostas dos profissionais das empresas inovadoras são maiores do que as médias apresentadas pelos profissionais das demais empresas.

Respondendo à pergunta da pesquisa, se o engajamento profissional pode agregar valor aos indicadores de desempenho estratégico nas organizações inovadoras, o resultado revela que sim, pois quando comparadas as médias de cada um dos níveis, é possível notar que, de forma geral, a diferença entre os níveis de engajamento dos funcionários das duas tipologias avaliadas é de cerca de 1 ponto a mais para aqueles das empresas classificadas como inovadoras.

Com a possível inclusão do índice de engajamento dentre os indicadores do BSC, particularmente na perspectiva aprendizagem e crescimento, demonstra-se o quanto o colaborador está engajado ou não em suas tarefas. A diferença entre os dois tipos de empresa foi discrepante, constatando que estar engajado no trabalho não é somente um sentimento agradável, mas também ser produtivo e desempenhar melhores resultados.

O estudo contribuiu com o campo de investigação dos resultados organizacionais ao apresentar aspectos significativos e essenciais, pois pontos positivos foram relevantes no entendimento da relação de indicadores de desempenho com o engajamento dos profissionais em organizações inovadoras.

Conforme os resultados obtidos, as empresas podem ter uma grande oportunidade de direcionar seus profissionais a alcançarem seus objetivos organizacionais, desde que invistam em treinamentos adequados, dependendo de cada área específica. Por exemplo, sabe-se que áreas como comercial, marketing, serviços são mais dinâmicas, que necessitam que seus 
colaboradores tenham mais energia, persistência em seus postos, mais resiliência, então com o resultado do teste, é possível corrigir esse déficit e potencializar este nível de engajamento, que é o vigor. Os resultados deste trabalho apontam também para que haja um estudo mais aprofundado no Brasil, com mais empresas participando da pesquisa, a fim de expandir os resultados consolidados sobre esta investigação e seus temas inclusos, e também para complementar o estado da arte na Gestão de Pessoas.

Assume-se, portanto, conforme o que se obteve neste estudo, que existem muitas empresas tidas como inovadoras, mas quando estas assumem a possibilidade de contribuir efetivamente com a educação, com a expansão de pesquisa no país, ao combate à estagnação do desenvolvimento e potencial humano, da falta de investimento público e servindo como uma fonte de conhecimento oriundo da iniciativa privada, muitas empresas listadas como inovadoras, infelizmente foram reativas a esta pesquisa, o que causa certo desapontamento.

No tocante à indicação para estudos futuros, sugere-se que o tema seja investigado por meio de propostas qualitativas, de modo a se obter resultados com maior detalhamento sobre o fenômeno do engajamento, tanto a partir de gestores quanto de profissionais que trabalhem em empresas inovadoras.

\section{Referências}

Bakker, A. B., \& Schaufeli, W. B. (2000). Burnout contagion processes among teachers. Journal of Applied Social Psychology, 30(11), 2289-2308.

Bakker, A. B., Schaufeli, W. B., Leiter, M. P., \& Taris, T. W. (2008). Work engagement: an emerging concept in occupational health psychology. Work \& Stress, 22(3), 187-200.

Bakker, A. B., \& Leiter, M. P. (2010). Work engagement: a handbook of essential theory and research. London: Psychology Press.

Bakker, A. B., Demerouti, E., \& Verbeke, W. (2004). Using the job demands: resources model to predict burnout and performance. Human Resources Management, 43, 83-104.

Boyatzis, R. E. \& Skelly, R. (1995). The impact of changing values on organization life. The latest update. New Jersey: Prentice Hall.

Bussab, W. O. \& Morettin, P. A. (2013). Estatística básica. (8a ed.). São Paulo: Saraiva. 
Csikszentmihalyi, M. (1992). A Psicologia da felicidade. São Paulo: Saraiva.

Daft, R. L. (2005). Administração. (6a ed.). São Paulo: Thomson.

Demerouti, E., Bakker A. B., Nachreiner F., \& Schaufeli, W. B. (2001). The job demandsresources model of burnout. Journal of Applied Psychology, 86(3), 499.

Demerouti, E., Bakker, A. B., \& Leiter, M. P. (2014). Burnout and job performance: the moderating role of selection, optimization, and compensation strategies. Journal of Occupational Health Psychology, 19, 96-107.

Dutra, J. S. (2014). Gestão de pessoas: modelo, processos, tendências e perspectivas. São Paulo: Atlas.

Drucker, P. F. (1987). Inovação e espírito empreendedor: prática e princípios. (H. T. Yoshizaqui, Trad.). São Paulo: Pioneira.

Fernandes, C. M., Siqueira, M. M. M., \& Vieira, A. M. (2014). Impacto da percepção de suporte organizacional sobre o comprometimento organizacional afetivo: o papel moderador da liderança. Revista Pensamento Contemporâneo em Administração, 8(4), 140-162.

Freitas, C. P. P., Silva, C. S. C., Damásio, B. F., Koller, S. H., \& Teixeira, M. A. P. (2016). Impact of job-related well-being on the relationship of self-efficacy with burnout. Paidéia, 26(63), 45-52.

Hair, J. F., Black, W. C., Babin, B. J., Anderson, R. E., \& Tatham, R. L. (1998). Multivariate data analysis. (5th ed.). Upper Saddle River: Pearson Prentice Hall.

Halbesleben Jonathon, R. B. \& Wheeler, A. R. (2008, july, september). The relative roles of engagement and embeddedness in predicting job performance and intention to leave. Work \& Stress, 22(3), 242-256.

Hobfoll, S. E. (2001). The influence of culture, community, and the nested-self in the stress process: advancing conservation of resources theory. Applied psychology, 50(3), 337421.

Kahn, W. A. (1990). Psychological conditions of personal engagement and disengagement at work. Academy of Management Journal, 33(4), 692-724.

Kaplan, R. S. \& Norton, D. P. (1997). A estratégia em ação: balanced scorecard. (L. E. T. Frazão Filho, Trad.). (21a ed.). Rio de Janeiro: Campus. 
Le Blanc, P. M., Schaufelli, W. B., Salanova, M., Lhorens, S., \& Nap, R. E. (2009). Efficacy beliefs predict collaborative practice among intensive care unit nurses. Journal of Advanced Nursing, 66 (3), 583-594.

Machado, P. G. B., Porto-Martins, P. C., \& Amorim, C. (2012). Engajamento no trabalho entre profissionais da educação. Revista Intersaberes, 7(13), 193-214.

Maslach, C., Jackson, S. E., \& Leiter, M. P. (1996). MBI Maslach Burnout Inventory. CPP: Incorporated.

Maslach, C., Schaufeli, W. B., \& Leiter, M. P. (2001). Job burnout. Annual review of psychology, 52(1), 397-422.

Maslach, C. \& Leiter, M. P. (2008). Early predictors of job burnout and engagement. Journal of Applied Psychology, 93(3), 498-512.

Medhurst, A. R. \& Albrecht, S. L. (2016). Salesperson work engagement and flow: qualitative exploration of their antecedents and relationship. Qualitative Research in Organizations and Management, 11 (1), 22-45.

Norton, D. P. \& Kaplan, R. B. (2004). Kaplan e Norton na prática. Rio de Janeiro: Elsevier.

Organização de Cooperação e Desenvolvimento Econômico. (1997.). Manual de Oslo: proposta de diretrizes para coleta e interpretação de dados sobre inovação tecnológica. [n. d.]: OCDE: FINEP.

Porter, M. (2000). A nova era da estratégia. HSM Management, 1(1), 18-28.

Salanova, M. \& Schaufeli, W. B. (2009). El engagement en el trabajo: cuando el trabajo se convierte en pasión. Madrid: Alianza editorial.

Schaufeli, W. B., Salanova, M., Gonzalez-Roma, V., \& Bakker, A. B. (2002). The measurement of engagement and burnout: a two sample confirmatory factor analytic approach. Journal of Happiness Studies, 3, 71-92.

Schaufeli, W. B. \& Salanova, M. (2007). Work engagement: an emerging psychological concept and its implications for organizations. In S. W. Gilliland, D. D. Steiner \& D. P. Skarlicki. Research in social issues in management (Volume 5): managing social and ethical issues in organizations. Greenwich, CT: Information Age Publishers. 
Schaufeli, W. B., Dijkstra, P., \& Vazquez, A. C. (2013). Engajamento no trabalho. São Paulo, SP: Casa do Psicólogo.

Schumpeter, J. (1961). Capitalismo, socialismo e democracia. Rio de Janeiro: Fundo de Cultura.

Senge, P. (1999). A quinta disciplina: arte e prática da organização que aprendo. (5a ed.) São Paulo: Best Seller.

Sharma, A. (2009). Implementing balanced scorecard for performance measurement. IUP Journal of Business Strategy, 6(1), 7.

Shi, Y., Sears, L. E., Coberley, C. R., \& Pope, J. E. (2013). The association between modifiable well-being risks and productivity: a longitudinal study in pooled employer sample. Journal of Occupational and Environmental Medicine, 55, 353-364.

Simpson, M. R. (2009). Engagement at work: a review of the literature. International Journal of Nursing Studies, 46, 1012-1024.

Siqueira, M. M. M. \& Gomide Jr., S. (2004). Vínculos do indivíduo com o trabalho e com a organização. Psicologia, organizações e trabalho no Brasil, 2, 317-348.

Siqueira, D. M. \& Vieira, A. M. (2012). Valores organizacionais: percepção e legitimação. Revista Gestão \& Tecnologia, 12(2), 168-191.

Vazquez, A. C., Magnan, E. S., Pacico, J. C., Hutz, C. S, \& Schaufeli, W. B. (2016). Avaliação do engajamento das pessoas com o seu trabalho: a versão brasileira da escala Utrecht de engajamento no trabalho (UWES). In C. S. Hutz (Org). Avaliação em Psicologia Positiva (75-89). São Paulo: Hogrefe.

Tamayo, A. \& Gondim, M. D. G. C. (1996). Escala de valores organizacionais. Revista de Administração da Universidade de São Paulo, 31(2).

Taris, T. W. (2006). Is there a relationship between burnout and objective performance? A critical review of 16 studies. Work \& Stress, 20, 316-334.

Taris, T. W. \& Schreurs, P. J. G. (2009). Well-being and organizational performance: an organizational-level test of the happy-productive worker hypothesis. Work \& Stress, 23, 120-136. 